\title{
Optimal policy for supply chain management system with retailer's hybrid payment strategy and supplier's price discount facility
}

\author{
Prasanta Ghosh ${ }^{1}$, AMALESH MANNA ${ }^{2}$, Jayanta Dey $^{3}$, and Samarjit $\operatorname{Kar}^{1}$ \\ ${ }^{1}$ NIT-Durgapur \\ ${ }^{2} \mathrm{C}$ V Raman Global University \\ ${ }^{3}$ Mahisadal Raj College, Mahisadal-721628, WB, India
}

February 28, 2022

\begin{abstract}
Suppliers often offer item-wise price discounts and trade credit to their retailers after receiving an initial payment for the supplied product. This discount is proportional to the total payment done already against the total cost accrued by the retailer. The supplier may also decide to allow the retailer to prepay a random part of the purchasing cost at any random time within the duration that an advance payment is allowed. In order to encourage the customers to increase their orders, the retailer, in turn, offers a trade-credit for a partial amount of the sale price to the customers. In this paper, we focus on the optimal replenishment policies of a retailer that could maximize the retailer's average profit when he/she is confronted with the supplier's trade offers of credit and price-discount under a two-layer supply chain management in a stochastic environment. We have obtained some theoretical results from the optimum cycle time and optimum order quantity of the proposed model and numerically analysed with a suitable example to demonstrate the real-life applicability of the model. Finally, sensitivity analyses are made on the significant parameters in order to gain some managerial insights.
\end{abstract}

\section{Hosted file}

Manuscript-04022022.pdf available at https://authorea.com/users/462811/articles/558124optimal-policy-for-supply-chain-management-system-with-retailer-s-hybrid-paymentstrategy-and-supplier-s-price-discount-facility 